\title{
Micro-scale characterization of surface recombination at the vicinity of laser processed regions in c-Si solar cells
}

\author{
A. Roigé, J. O. Ossó, I. Martín, C. Voz, P. Ortega, J. M. López-González, R. Alcubilla, and L. F. Vega
}

\begin{abstract}
Laser firing processes have emerged as a technologically feasible approach to fabricate local point contacts or local doped regions in advanced high-efficiency crystalline-Si (c-Si) solar cells. In this work we analyze the local impact induced by the laser pulse on the passivation layers, which are commonly present in advanced c-Si solar cell architectures to reduce surface recombination. We use micro-photoluminescence (PL) measurements with a spatial resolution of $7 \mu \mathrm{m}$ to evaluate the passivation performance at the surroundings of laser processed regions (LPRs). In particular, we have studied LPRs performed on $\mathrm{SiC}_{x} / \mathrm{Al}_{2} \mathrm{O}_{3}-$ and $\mathrm{Al}_{2} \mathrm{O}_{3}$-passivated $\mathrm{c}-\mathrm{Si}$ wafers by an IR $(1064 \mathrm{~nm})$ laser. Micro-PL results show that passivation quality of c-Si surface is affected up to about $100 \mu \mathrm{m}$ away from the LPR border, and that the extension of this damaged zone is correlated to the laser power and to the presence of capping layers. In the final part of the work, the observed decrease in passivation quality is included into an improved 3D simulation model that gives accurate information about the recombination velocities associated to the studied LPRs.
\end{abstract}

\section{Index Terms}

Crystalline silicon, laser processing, surface passivation, micro-photoluminescence spectroscopy.

\section{INTRODUCTION}

Nowadays, crystalline-Si (c-Si) solar cell efficiencies reach values well above $20 \%$ thanks to the development of advanced high-efficiency c-Si solar cell structures [1]. A very promising and industrially feasible approach to fabricate these advanced solar cell architectures is laser processing. In this approach, a laser beam fires the surface of a solar cell, to create, for instance, local heavily doped regions [2], [3], or point-like contacts, the so-called laser fired contacts (LFCs) [4]-[6].

Laser-processed regions (LPRs) are formed by a local melting-solidification step, thus, the structure of the processed material volume is strongly affected. This fact has been demonstrated by the detection of dislocations [7] and certain levels of mechanical stress [8], [9] in the regions processed by laser. In addition to these micro-structural studies, other analysis such as the study of the composition [10], the estimation of the doping level [8], [9], and the study of the electronic properties [11], [12] of LPRs have been also carried out in the last years. Most of these investigations are exclusively focused on the study of the features and properties of the locally molten material volume, however, no detailed analyses at the surrounding area of LPRs have been performed up to now. During the laser pulse length (typically ranging from tens of nanoseconds to hundreds of microseconds) local temperature reaches values above the silicon melting temperature, i.e. $1414{ }^{\circ} \mathrm{C}$, and therefore, the vicinity of LPRs is believed to suffer extremely high thermal gradients. As suggested by Glunz et al. [13], this may induce important damage on the passivation capabilities around the processed region, decreasing the effective surface passivation in such area, and therefore, reducing in turn the final solar cell performance.

Photoluminescence (PL) spectroscopy has been extensively employed during the last decades for the rapid and non-invasive characterization of passivation materials performance [14]-[16]. In the present work, micro-PL spectroscopy measurements with a lateral resolution of around $7 \mu \mathrm{m}$ have been carried out at the surroundings of LPRs in order to study the impact of laser processing on the passivation capabilities of dielectric layers. In particular, we have studied LPRs in silicon carbide/aluminum oxide $\left(\mathrm{SiC}_{x} / \mathrm{Al}_{2} \mathrm{O}_{3}\right)$ - and $\mathrm{Al}_{2} \mathrm{O}_{3}$-passivated c-Si wafers. As recently reported, when $\mathrm{Al}_{2} \mathrm{O}_{3}$ is used as passivation layer, the alumina film acts as $\mathrm{Al}$ (p-type) dopant source and then the laser processing can be used for both creating selective emitters (in n-type c-Si wafers) [17] or laser fired contacts (LFCs) (in p-type c-Si wafers) [6].

Here, we show that the passivation efficiency decreases at the nearby regions of the laser-processed surface and that this decrease in passivation efficiency is correlated to the laser power, as well as to the particular dielectric stack. In addition, we have also carried out micro-Raman spectroscopy measurements in order to analyze if the c-Si structure around the LPRs suffers variations during the laser processing. In the final part of the work, a 3D model that takes into account the decrease in passivation observed around the LPRs is proposed for determining the surface recombination velocity at the laser-processed surface.

\section{EXPERIMENTAL METHODS AND MATERIALS}

All the samples were based on p-type (boron-doped) float zone (FZ) crystalline silicon (c-Si) wafers with (100) orientation, a thickness of $250 \mu \mathrm{m}$ and a resistivity of $2.5 \Omega \mathrm{cm}$. After an RCA cleaning sequence, a $25 \mathrm{~nm}$-thick layer of $\mathrm{Al}_{2} \mathrm{O}_{3}$ was 
deposited on both wafer sides by thermal atomic layer deposition (ALD) in a Cambridge Nanotech Savannah S200 system at a temperature of $200{ }^{\circ} \mathrm{C}$. During the process the surface of the substrate was alternatively exposed to $\mathrm{Al}\left(\mathrm{CH}_{3}\right)_{3}$ (TMA) and $\mathrm{H}_{2} \mathrm{O}$ as precursors. The reactions were cyclical and each reaction was purged by means of $\mathrm{N}_{2}$ to remove the reactants and the reaction products. Next, some of the samples were also coated with a $50 \mathrm{~nm}$-thick capping layer of PECVD $\mathrm{SiC}_{x}$ leading to the formation of $\mathrm{SiC}_{x} / \mathrm{Al}_{2} \mathrm{O}_{3}$ stacks. Finally, both $\mathrm{Al}_{2} \mathrm{O}_{3}$ and $\mathrm{SiC}_{x} / \mathrm{Al}_{2} \mathrm{O}_{3}$ samples were annealed in forming gas $\left(\mathrm{N}_{2} / \mathrm{H}_{2}\right)$ at a temperature of $375{ }^{\circ} \mathrm{C}$ for $15 \mathrm{~min}$. In all the samples laser processing was performed by a $1064 \mathrm{~nm} \mathrm{Nd}$ :YAG lamp-pumped laser with a pulse duration of $100 \mathrm{~ns}$. Each contact is the result of 6 laser pulses with a frequency of $4 \mathrm{kHz}$. We used laser powers of $0.83,0.98$ and $1.44 \mathrm{~W}$ corresponding to an energy per pulse of $0.207,0.245$ and $0.36 \mathrm{~mJ}$, respectively.

Topography maps of LFCs were obtained by optical profilometry (KLA-Tencor). The experimental setup for micro-PL measurements (and micro-Raman measurements that is roughly the same) is depicted in Fig.1. Micro-PL and micro-Raman spectroscopy measurements were carried out with a LabRam HR Raman spectrometer (Horiba Jobin Yvon). For micro-PL measurements a diode-pumped solid-state laser (SSL) with a wavelength of $785 \mathrm{~nm}$ was used as excitation source, and the backscattered PL signal was recorded by an infrared (IR) photodiode detector. The excitation laser beam was modulated by an optical chopper at a frequency of $130 \mathrm{~Hz}$ to amplify the generated PL signal by a Lock-in amplifier. Due to the short lifetime of the photo-generated carriers, the light beam modulation at $130 \mathrm{~Hz}$ ensured steady state conditions. The micro-PL configuration was obtained by focusing the excitation laser beam onto the sample surface by a 50x microscope objective (Leica) with a numerical aperture (NA) of 0.55 . The resulting beam spot size was around $7 \mu \mathrm{m}$ in diameter. Due to such small spot size, the excitation power density on the sample surface resulted to be in the order of $8 \times 10^{4} \mathrm{~W} / \mathrm{cm}^{2}$, leading to a density of photo-generated carriers well above $10^{18} \mathrm{~cm}^{-3}$. As reported by Gundel et al. [19], under these high injection levels, Auger recombination limits the carrier diffusion length to $1 \mu \mathrm{m}$ or less, which therefore, gives us a spatial resolution for the PL measurements in the order of the laser beam spot size. For micro-Raman measurements, the light excitation was made by the same diode-pumped SSL (wavelength of $785 \mathrm{~nm}$ ), and again the light beam was focused onto the sample surface by the same Leica 50x microscope objective. In this case, the inelastic scattering signal was collected by a charge-coupled device (CCD) cooled at $135 \mathrm{~K}$.

\section{RESULTS AND DISCUSSION}

\section{A. Micro-PL characterization of LPRS}

Fig. 2(a) shows a topography map of a LPR performed at $1.44 \mathrm{~W}$ in a $\mathrm{SiC}_{x} / \mathrm{Al}_{2} \mathrm{O}_{3}$-passivated c-Si wafer. The corresponding topography and normalized PL profiles are depicted in Fig. 2(b) and Fig. 2(c), respectively. The topography profile shows the morphology of the LPR cross-section, and therefore it also allows the accurate correlation of both topography and PL profiles (the LPR borders are defined by the black vertical dashed lines). The signal of the depicted PL profile corresponds to the PL intensity at $1.1 \mathrm{eV}$ where the PL spectrum (not shown) evidences the maximum intensity value correlated to the $\mathrm{Si}$ band-to-band radiative recombination. As deduced by the low noise of the represented PL profile, we confirm that all the PL data presented in this work were obtained from a meaningful and stable PL signal.

As c-Si is an indirect band gap semiconductor in which non-radiative processes are dominant mechanisms, and taking into account that radiative and non-radiative are competitive processes, a maximum value of PL implies a minimum rate of nonradiative recombination. Thus, assuming that bulk recombination is negligible in front of surface recombination processes (as it is the case in our high quality FZ c-Si wafers), we can qualitatively conclude that the higher the PL intensity the better the

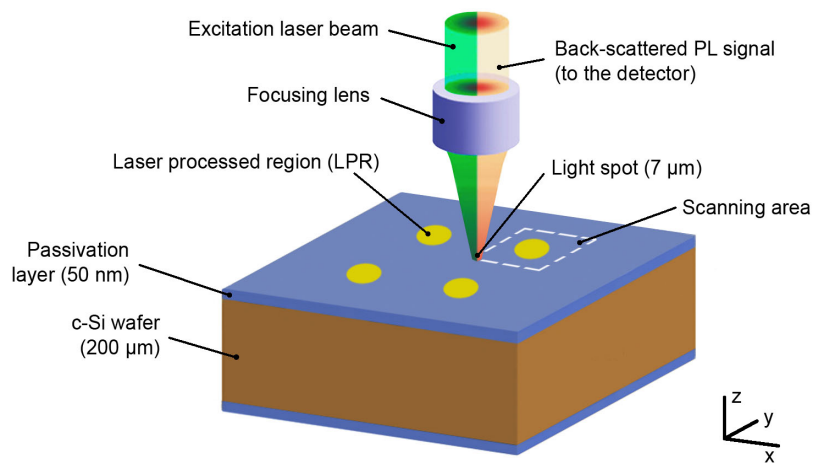

Fig. 1. Sketch of the experimental setup for micro-PL measurements. The laser beam is focused onto the sample surface by a focusing lens, and the backscattered PL signal is collected while the focused spotlight scans the surroundings of the laser processed region (LPR). 
performance of the passivation layer. As it can be seen, the PL profile of Fig. 2(c) shows a maximum PL value at the further points from the LPR border ( $\mathrm{x}=-150$ and $150 \mu \mathrm{m}$ ). This maximum value of PL recorded far away from the laser spot corresponds to a non-affected point of the sample surface and is associated to the effective surface recombination velocity provided by the dielectric film. This magnitude was calculated from lifetime measurements using quasi steady state-photoconductance (QSSPC) technique. In all the samples lifetime values were in the 1.5 to $2.5 \mathrm{~ms}$ range resulting in $S_{\text {eff }}$ values of $5-10 \mathrm{~cm} / \mathrm{s}$. From the mentioned point with a maximum PL intensity we observe that the PL signal decreases progressively when it gets closer to the laser spot border, demonstrating a reduction of the passivation quality around the LPR. This reduction of the PL intensity can be semi-quantified by a PL loss (dashed shaded area of Fig. 2(c)). In particular, this PL loss can be considered as the amount of passivation loss induced by the laser firing process at the vicinity of the LPRs. Thus, from now on, the integration of this PL loss will be used to semi-quantify the impact of the laser process and to compare data from different measurements. Concerning the integration limits in the $\mathrm{x}$-axis, the integral was calculated from the physical border of the LPR (vertical dashed line) up to $100 \mu \mathrm{m}$ away from that limit.

Fig. 3 represents the normalized PL profiles recorded from LPRs performed at $0.83,0.98$ and $1.44 \mathrm{~W}$ on (a) $\mathrm{SiC}_{x} / \mathrm{Al}_{2} \mathrm{O}_{3}-$ and (b) $\mathrm{Al}_{2} \mathrm{O}_{3}$-passivated c-Si wafers. For the sake of clarity, the PL profiles plotted here only show one half of the complete PL profile contact shown in Fig. 2(c). Note that the PL signal has been normalized to its maximum PL value for comparing different measurements and samples. In addition, the LPR border (defined by the vertical dashed line) has been positioned at $\mathrm{x}=0 \mu \mathrm{m}$ to help in the comparison among different PL profiles. As already observed in Fig. 2, all the PL profiles here show a significant PL loss at the LPR vicinity that we attribute to a reduction of the passivation quality. In particular, a decay of the passivation quality up to approximately $100 \mu \mathrm{m}$ away from the spot border limit is observed for the LPRs performed at $1.44 \mathrm{~W}$. The line integrated PL loss correlated to the 6 PL profiles represented in Fig. 3(a) and Fig. 3(b) has been calculated and it is shown in Fig. 3(c). In this figure it can be seen that the impact of the laser pulse on the passivation layer increases progressively with increasing laser power. An interesting parameter is the PL loss quantification divided by the laser spot diameter, which is

a)

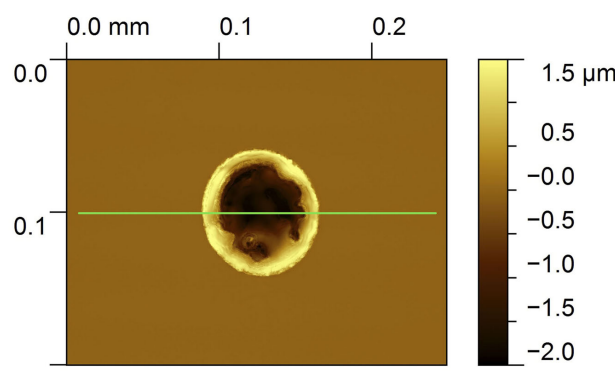

b)

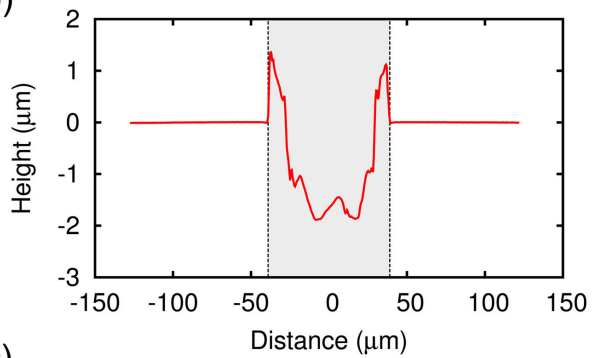

c)

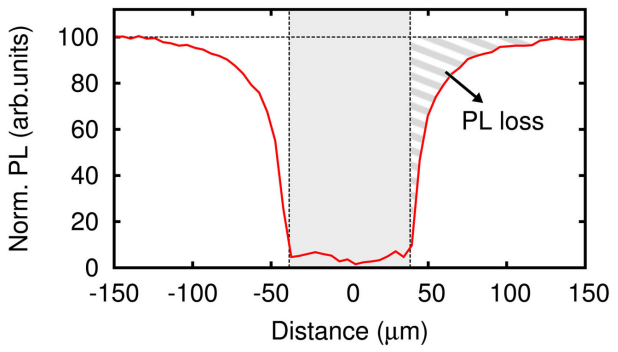

Fig. 2. Topography map (a) of a single $\mathrm{LPR}$ on a $\mathrm{SiC}_{x} / \mathrm{Al}_{2} \mathrm{O}_{3}$-passivated c-Si wafer. The green line defines the horizontal cross-section from which topography (b) and normalized PL (c) profiles were obtained. The gray colored area in b) and c) represents the limits of the laser spot. The dashed shaded area in c) defines the PL loss at the LPR surroundings. 

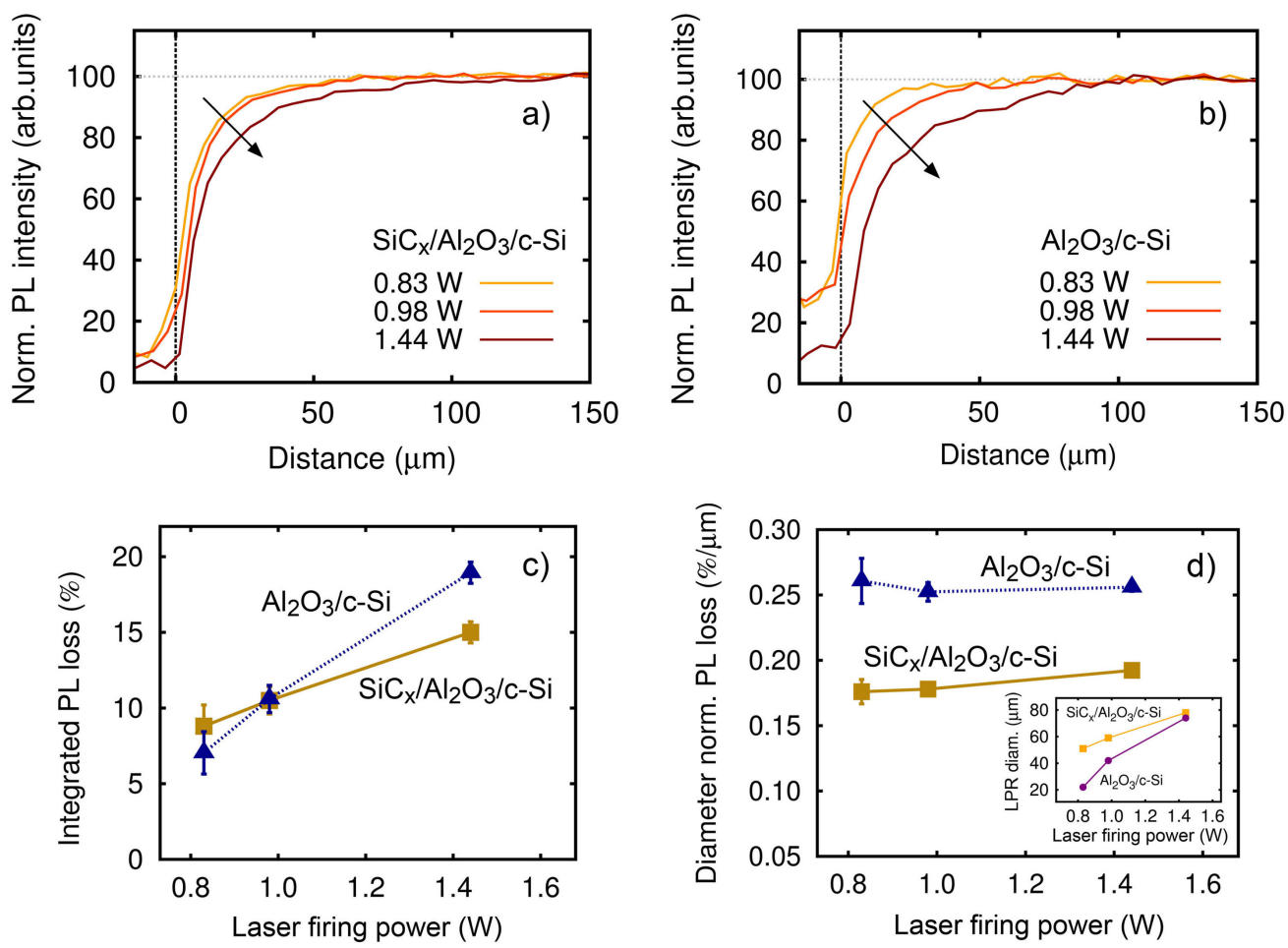

Fig. 3. Normalized PL profiles at the vicinity of LPRs performed at $0.83,0.98$ and $1.44 \mathrm{~W}$ on $\mathrm{SiC}_{x} / \mathrm{Al}_{2} \mathrm{O}_{3} / \mathrm{c}-\mathrm{Si}$ (a) and $\mathrm{Al}_{2} \mathrm{O}_{3} / \mathrm{c}-\mathrm{Si}$ (b) samples. The vertical dashed line at $\mathrm{x}=0 \mu \mathrm{m}$ defines the border of the LPRs. The PL loss quantification of the 6 PL profiles depicted in a) and b) is represented in percentage (c) and also normalized by the corresponding LPR diameters (d). The diameters of the different LPRs are shown in the inset.

shown in Fig. 3(d) and tells us the effect of the $\mathrm{SiC}_{x}$ capping layer on the impact induced by laser processing. The normalized PL loss reveals that the reduction in passivation efficiency is much lower for the sample with the capping layer for the same spot diameter. In a previous work [6], we show that the effective surface recombination velocity at the laser processed surface of $\mathrm{SiC}_{x} / \mathrm{Al}_{2} \mathrm{O}_{3}$-passivated c-Si is significantly lower than that measured at the laser processed surface of $\mathrm{Al}_{2} \mathrm{O}_{3}$-passivated $\mathrm{c}-\mathrm{Si}$. The obtained PL profiles suggest that the lower laser-induced impact in the spot surroundings observed in the samples with $\mathrm{SiC}_{x}$ capping layer would be partially responsible of their better performance.

\section{B. Laser-induced impact on the c-Si wafer}

In order to identify whether the reduction in passivation performance observed around the LPRs is only attributed to changes at the c-Si/dielectric interface or it is also related to changes in the c-Si wafer at the sub-surface region, we repeated the microPL measurements in the $\mathrm{Al}_{2} \mathrm{O}_{3}$-passivated c-Si wafers after removing the $\mathrm{Al}_{2} \mathrm{O}_{3}$ film. The obtained normalized PL profiles are shown in Fig. 4. As it can be seen, the PL profiles do not evidence any PL loss at the LPR surroundings, showing, apparently, that laser firing processes do not affect the c-Si wafer.

It is worth to mention that the PL profile of the $1.44 \mathrm{~W}$ LFC for the HF-etched sample shows an unexpected feature. In particular, from 10 to $130 \mu \mathrm{m}$ of the x-axis, the PL profile shows a region with a higher PL intensity than the PL value related to a non-affected point of the sample surface $(\mathrm{x}=150 \mu \mathrm{m})$. We attribute this effect to a thermally-induced $\mathrm{Al}$ crystallization from the $\mathrm{Al}_{2} \mathrm{O}_{3}$ layer taking place during laser processing, and which could not be eliminated by the HF etching process. This hypothesis is strengthened by KPFM measurements of such an area (data not shown) where small structures of 100-200 nm in size with a different KPFM signal than c-Si have been observed. Note that this region with a higher PL is not observed for the PL profiles related to the spots processed at laser powers below $1.44 \mathrm{~W}$. We further confirm that neither the small structures with a different KPFM signal were observed for such laser power values. In contrast, the local increase in PL intensity, and also the small structures detected in KPFM measurements, were observed at the surroundings of LPRs performed at $2 \mathrm{~W}$ (data not shown).

In order to further verify that the c-Si structure is not modified around the LPRs, we have carried out micro-Raman spectroscopy measurements along the same LPRs. The study of the line-shape of the first order c-Si Raman peak can give us important information about specific c-Si properties like doping [20], crystallinity [21] or mechanical stress [22]. Raman 
results are shown in Fig. 5. As it can be observed, the characteristic transverse optical (TO)-phonon mode of c-Si $\left(520.9 \mathrm{~cm}^{-1}\right)$ evidences a Raman shift at the very central point of the spot (point 3), whereas points out of the laser spot (point 1 and point 5 ), and even points in the outer region inside the spot (point 2 and 4), do not evidence any change at all. The red shift at the central part of the laser spot, which increases for a LPRs performed at $2 \mathrm{~W}$ (gray spectrum with crossed points), is representative of a stressed Si structure [22], and can be induced by the laser processing. These conclusions are in agreement with an exhaustive micro-Raman spectroscopy analysis of LPRs presented elsewhere [9]. In particular, such study reveals that c-Si structure only suffers structural changes inside the laser-processed spot, but not at the surrounding regions. With all these findings, we confirm that the reduction in passivation efficiency observed at the vicinity of LPRs is solely linked to a worsening of the passivation capabilities of the dielectric layer.

\section{Recombination velocity at the laser-processed surface}

The effect of laser processing on the effective rear surface recombination velocity $\left(S_{\text {eff }}\right)$ in $\mathrm{SiC}_{x} / \mathrm{Al}_{2} \mathrm{O}_{3} / \mathrm{c}$-Si stacks is represented in Fig. 6. $\mathrm{S}_{\text {eff }}$ was calculated from the effective lifetime at 1 sun measured by QSSPC (Sinton WCT-120), and it is represented as a function of the pitch. The diameter of the laser spots was measured to be $50 \mu \mathrm{m}$ and a laser power of $1.1 \mathrm{~W}$ was used to process them. Data from four $\mathrm{SiC}_{x} / \mathrm{Al}_{2} \mathrm{O}_{3} / \mathrm{c}$-Si samples with pitch values of $600,400,250$, and $175 \mu \mathrm{m}$ are represented. Experimental results are adjusted by Fischer's model [23], [24], which is usually used to predict $S_{\text {eff }}$ of squared matrix layouts of point contacts by considering a surface recombination velocity at the regions processed by laser $\left(S_{\text {laser }}\right)$ and a surface recombination velocity at the non-processed area $\left(S_{\text {pass }}\right)$. In this case, Fischer analytical model could be correctly

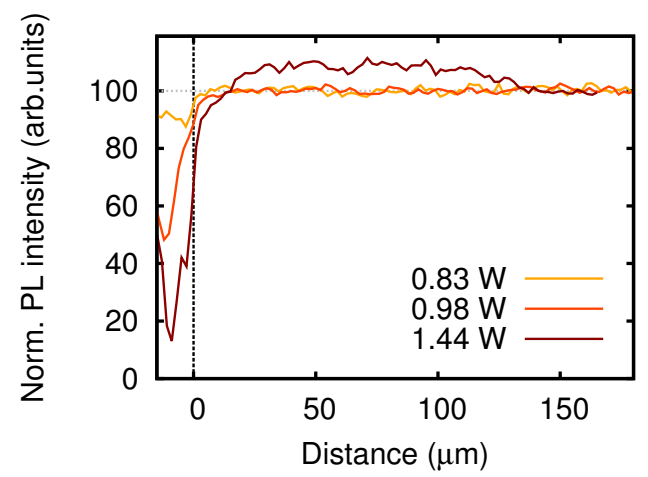

Fig. 4. Normalized PL profiles at the vicinity of LPRs after the $\mathrm{Al}_{2} \mathrm{O}_{3}$ layer was removed.

a)

b)

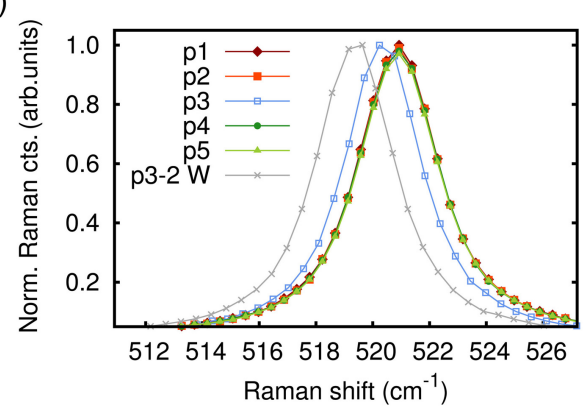

Fig. 5. Image of a laser spot obtained with our Raman spectrometer confocal microscope (a) showing the points where normalized Raman spectra (b) were recorded. The spectra show the Raman shift of the characteristic transverse-optical (TO) phonon mode of c-Si. For the sake of clarity, Raman spectra corresponding to points $\mathrm{p} 2, \mathrm{p} 4$ and $\mathrm{p} 5$ (which exactly match the spectrum of point p1) have been represented with a factor of $0.99,0.98$ and 0.97 , respectively. 
TABLE I

$S_{\text {pass }}$ AND $S_{\text {laser }}$ PARAMETERS ObTAINED FROM THE TWO FITTING CURVES DEPICTED IN Fig. 6.

\begin{tabular}{lll}
\hline & $S_{\text {pass }}$ & $S_{\text {laser }}$ \\
\hline Fischer's model & $6 \mathrm{~cm} / \mathrm{s}$ & $1700 \mathrm{~cm} / \mathrm{s}$ \\
Our 3D model & $6 \mathrm{~cm} / \mathrm{s}$ & $450 \mathrm{~cm} / \mathrm{s}$ \\
\hline
\end{tabular}

adjusted to the experimental data using a $S_{\text {laser }}$ of $1700 \mathrm{~cm} / \mathrm{s}$ and a $S_{\text {pass }}$ of $6 \mathrm{~cm} / \mathrm{s}$, the latter treated as an input parameter from a $\mathrm{SiC}_{x} / \mathrm{Al}_{2} \mathrm{O}_{3}$-passivated c-Si wafer without laser processing. Additionally, experimental data were also adjusted by our proposed 3D model defined in Silvaco Altlas [25], which incorporates the passivation quality reduction observed at the LPRs surroundings. The recombination velocity profiles correlated to both models are represented in the inset of Fig. 6 . As mentioned above, in contrast to Fischer's model that considers no transition between the laser spots region and the non-processed surface, our model considers an exponential decay between $S_{\text {laser }}$ and $S_{\text {pass }}$ that agrees with micro-PL measurements.

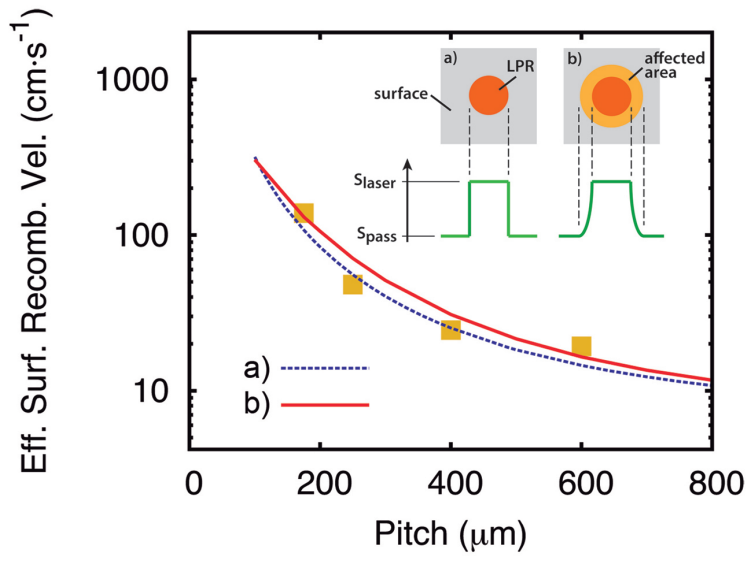

Fig. 6. Effective surface recombination velocity at the laser processed side of a $\mathrm{SiC}_{x} / \mathrm{Al}_{2} \mathrm{O}_{3} / \mathrm{c}$-Si sample as a function of the pitch. Experimental data were adjusted to the Fischer's model (curve a). Additionally, data were also adjusted to our 3D model (curve b). The recombination velocity profiles associated to each one of the two models are represented in the inset for a single laser spot.

Both curves fit well with experimental data. However, as shown in Table I, the relevant difference is related to the fact that the 3D model gives a $S_{\text {laser }}$ value of $450 \mathrm{~cm} / \mathrm{s}$, in front of the $1700 \mathrm{~cm} / \mathrm{s}$ obtained from the Fischer's model. Since Fischer's model does not consider the decay in the surface passivation at the LPR surroundings, the model incorporates this additional recombination to a higher $S_{\text {laser }}$ where all the calculated recombination (laser spot + laser spot vicinity) is considered. The more accurate 3D model yields a more precise picture of the surface recombination. This valuable information can be used to further improve the quality of the LPRs. For example, the low $S_{\text {laser }}$ value indicates a very good quality of the p+ regions below the laser spots and that the limiting factor is the passivation loss at the spot surroundings.

\section{CONCLUSION}

To summarize, in the present work, we used micro-PL spectroscopy measurements in order to study the local effect of laser firing processes on the performance of passivation layers in advanced c-Si solar cell architectures. LPRs performed on $\mathrm{SiC}_{x} / \mathrm{Al}_{2} \mathrm{O}_{3} / \mathrm{c}-\mathrm{Si}$ and $\mathrm{Al}_{2} \mathrm{O}_{3} / \mathrm{c}$-Si samples showed a significant impact on the passivation layer performance. In particular, for LPRs performed at $1.44 \mathrm{~W}$, a reduction of the passivation performance has been observed up to a distance of $100 \mu \mathrm{m}$ from the LPR border. Interestingly, the impact on the passivation layer was observed to be lower in the $\mathrm{SiC}_{x} / \mathrm{Al}_{2} \mathrm{O}_{3} / \mathrm{c}$-Si. This suggests that the presence of a $\mathrm{SiC}_{x}$ capping layer minimizes the impact of the laser pulse. Finally, we have proposed a 3D simulation model to predict the effective surface recombination velocity of laser-processed surfaces taking into account the local decrease in passivation deduced from micro-PL measurements. Compared to commonly used 1D models, which incorporate the observed passivation reduction in the recombination velocity assigned to the laser spots, our model gives a more accurate picture of surface recombination at surfaces processed by laser, and thus, it can be useful to further optimize laser processing applications such as laser doping or local point contacts, i.e. laser fired contacts (LFCs).

\section{REFERENCES}

[1] A. W. Blakers, A. Wang, A. M. Milne, J. Zhao and M. A. Green, “22.8\% efficient silicon solar cell”, Appl. Phys. Lett., vol. 55, pp. 1363-1365, 1989. 
[2] B. S. Tjahjono, J. H. Guo, Z. Hameiri, L. Mai, A. Sugiante, S. Wang and S. R. Wenham, "High efficiency solar cell structures through the use of laser doping", in Proc. 22nd EUPVSEC, 2007, pp. 966-969.

[3] A. Orpella, I. Martín, S. Blanque, C. Voz, I. Sánchez, M. Colina, C. Molpeceres and R. Alcubilla, "Optimization of lasser processes in n+ emitter formation for c-Si solar cells", in Proc. 24th EUPVSEC, 2009, pp. 1798-1802.

[4] E. Schneiderlöchner, R. Preu, R. Ldemann and S. W. Glunz, "Laser-fired rear contacts for crystalline silicon solar cells", Prog. Photovolt.: Res. Appl., vol. 10, pp. 29-34, 2002.

[5] W. Brendle, V. X. Nguyen, A. Grohe, E. Schneiderlöchner, U. Rau, G. Palfinger, J. H. Werner, "20.5\% efficient solar cell with a low temperature rear side process using laser fired contacts", Prog. Photovolt.: Res. Appl., vol. 14, pp. 653-662, 2006.

[6] P. Ortega, A. Orpella, I. Martín, M. Colina, G. Lopez, C. Voz, M. I. Sanchez, C. Molpeceres and R. Alcubilla, "Laser-fired contact optimization in c-Si solar cells", Prog. Photovolt.: Res. Appl., vol. 20, pp. 173-180, 2012.

[7] H. T. Nguyen, Y. Han, M. Ernst, A. Fell, E. Franklin and D. Macdonald, "Dislocations in laser-doped silicon detected by micro-photoluminescence spectroscopy", Appl. Phys. Lett, vol. 107, p. 022101, 2015.

[8] P. Gundel, D. Suwito, U. Jager, F. Heinz, W. Warta and M. Schubert, "Comprehensive microscopic analysis of laser-induced high doping regions in silicon", IEEE Trans. Electron Devices, vol. 58, pp. 2874-2877, 2011.

[9] A. Roigé, J. Alvarez, J.-P. Kleider, I. Martín, R. Alcubilla and L. F. Vega, "Microscale spatially-resolved characterization of highly-doped regions in laser-fired contacts for high-efficiency crystalline Si solar cells", IEEE J. Photovolt., vol. 5, pp. 545-551, 2015.

[10] U. Zastrow, L. Houben, D. Meertens, A. Grohe, T. Brammer and E. Schneiderlöchner, "Characterization of laser-fired contacts in PERC solar cells: SIMS and TEM analysis applying advanced preparation techniques", Appl. Surf. Sci., vol. 252, pp. 7082-7085, 2006.

[11] V. Naumann, C. Hagendorf, M. Werner, B. Henke, C. Schmidt, J. Nekarda and J. Bagdahn, "Local electronic properties and microstructure of individual laser-fired contacts", in Proc. 24th EUPVSEC, 2009, pp. 2180-2184.

[12] S. W. Glunz, J. Nekarda, H. Mckel and A. Cuevas, "Analyzing back contacts of silicon solar cells by Suns-Voc-measurements at high illumination densities", in Proc. 22nd EUPVSEC, 2007.

[13] S. W. Glunz, A. Grohe, M. Hermle, E. Schneiderlöchner, J. Dicker, R. Preu, H. Mäckel, D. Macdonald and A. Cuevas, "Analysis of laser-fired local back surface fields using $\mathrm{n}+\mathrm{np}+$ cell structures", in Proc. 3rd World Conference Photovoltaic Energy Conversion, 2003, pp. 1332-1335.

[14] T. Trupke and R. A. Bardos. "Photoluminescence: A surprisingly sensitive lifetime technique", in Proc. 31th IEEE Photovoltaic Specialists Conference, 2005, pp. 903-906.

[15] S. Herlufsen, J. Schmidt, D. Hinken, K. Bothe and R. Brendel, "Photoconductance-calibrated photoluminescence lifetime imaging of crystalline silicon", Phys. Stat. Sol. RRL, vol. 2, pp. 245-247, 2008.

[16] J. A. Giesecke, M. C. Schubert, D. Walter and W. Warta, "Minority carrier lifetime in silicon wafers from quasi-steady-state photoluminescence", Appl. Phys. Lett., vol. 97, p. 092109, 2010.

[17] I. Martín, A. Coll, G. Lópes, P. R. Ortega, T. Desrues, A. Orpella and R. Alcubilla, "TCO-free low-temperature p+ emitters for back-junction c-Si solar cells", Energy Procedia, vol. 77, pp. 292-303, 2015.

[18] P. Ortega, I. Martin, G. Lopez, M. Colina, A. Orpella, C. Voz and R. Alcubilla, "P-type c-Si solar cells based on rear side laser processing of $\mathrm{Al}_{2} \mathrm{O}_{3} / \mathrm{SiC}_{x}$ stacks", Sol. Energy Mat. Sol. C., vol. 106, pp. 80-83, 2012.

[19] P. Gundel, F. D. Heinz, M. C. Schubert, J. A. Giesecke and W. Warta, "Quantitative carrier lifetime measurement with micron resolution", J. Appl. Phys., vol. 108, p. 033705, 2010.

[20] M. Becker, U. Gösele, A. Hofmann and S. Christiansen, "Highly p-doped regions in silicon solar cells quantitatively analyzed by small angle beveling and micro-Raman spectroscopy", J. Appl. Phys., vol. 106, p. 074515, 2009.

[21] Z. Iqbal, S. Veprek, A. Webb and P. Capezzuto, "Raman scattering from small particle size polycrystalline silicon", Solid State Commun., vol. 37, pp. 993-996, 1981.

[22] R. M. B. Agaiby, M. Becker, S. B. Thapa, U. Urmoneit, A. Berger, A Gawlik, G. Sarau and S. H. Christiansen, "Stress and doping uniformity of laser crystallized amorphous silicon in thin film silicon solar cells", J. Appl. Phys., vol. 107, p. 054312, 2010.

[23] B. Fischer, "Loss analysis of crystalline silicion solar cells using photoconductance and quantum efficiency measurements", Ph.D. dissertation, Universität Konstanz, 2003.

[24] H. Plagwitz and R. Brendel, "Analytical model for the diode saturation current of point-contacted solar cells", Prog. Photovolt: Res. Appl., vol. 14, pp. 1-12, 2006.

[25] ATLAS device simulation framework, http://www.silvaco.com/products/device_simulation/atlas.html 